\title{
FORMAÇÃO EXECUTIVA EM BIM: EXPERIÊNCIAS DIDÁTICAS NA FGV
}

\section{Modalidade: Experiência de ensino-aprendizagem BIM realizadas}

\section{REALIZAÇÃO DAS DISCIPLINAS}

0 programa do curso é composto por 4 disciplinas de caráter gerencial: (1) Fundamentos BIM, (2) Gestão Organizacional BIM, (3) Estratégias de Implementação BIM e (4) Plano de Execução BIM. A carga horária total é de 64 horas, sendo 16 horas para cada disciplina, distribuídas igualmente em 4 aulas. A abordagem é teórico-prática, com a parte prática direcionada ao desenvolvimento de trabalhos voltados para estruturas organizacionais, mapas de processos e planos BIM. Neste sentido, os softwares utilizados se restringem a ferramentas de apoio às dinâmicas como, por exemplo, Slido, Jamboard.
As aulas ficam gravadas e disponíveis em ambiente de sala virtual da FGV, proporcionando melhor fixação e possibilidade de revisão do conteúdo. No encerramento de cada disciplina é realizado uma avaliação. Na disciplina (1) a avaliação envolve um trabalho sobre os conceitos BIM, na disciplina (2) um trabalho sobre novos papéis $e$ responsabilidades BIM, na disciplina (3) e (4) os alunos desenvolvem partes de um Plano de Implementação BIM e de um Plano de execução BIM, respectivamente. Além disso, ao final de cada disciplina é realizada uma avaliação pelos alunos, onde colocam a percepção geral do curso.

Figura 1: Sugestões observadas pelos alunos em relação ao curso

AVALIAÇÃO A

(TURMA FECHADA- EMPRESA DE INFRAESTRUTURA)

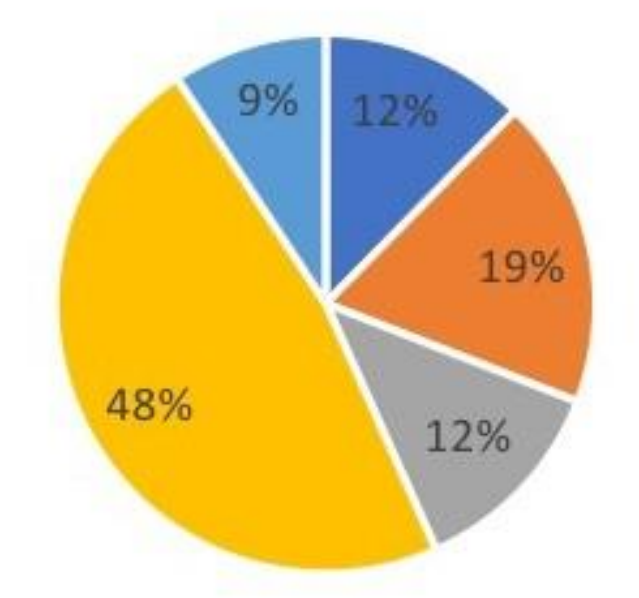

- MAIS EXEMPLOS PRÁTICOS EM INFRAESTRUTURA

- DIMINUIR CARGA HORÁRIA

- O CURSO CUMPRIU AS EXPECTATIVAS

- SEM SUGESTÕES

- OUTROS
AVALIAÇÃO B

(TURMAS ABERTAS)

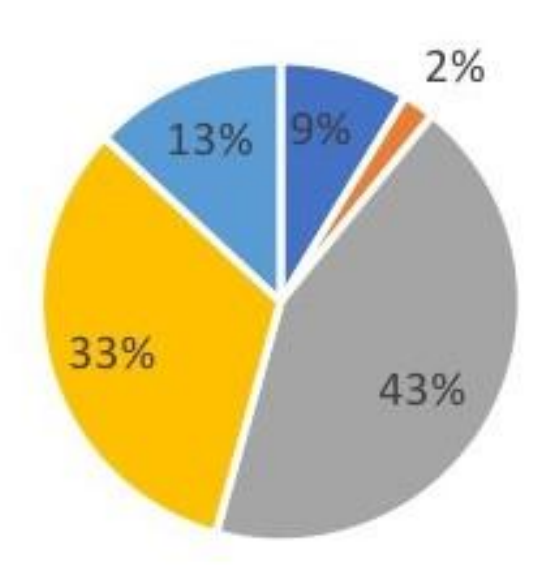

- MAIS EXEMPLOS PRÁTICOS

- DIMINUIR CARGA HORÁRIA

- O CURSO CUMPRIU AS EXPECTATIVAS

= SEM SUGESTÕES

- OUTROS

\section{LIÇÕES APRENDIDAS}

Um curso focado nas competências gerenciais BIM é um grande desafio tendo em vista que a maioria dos cursos são de habilidades tecnológicas BIM. De acordo com a figura 1, as disciplinas foram bem avaliadas pelos alunos em ambas as turmas. Alguns pontos levantados refletem alguns cenários BIM, como mais exemplos práticos em infraestrutura, tema que até então tem menos ênfase nas práticas BIM.

0 curso está mais voltado para perfis de alunos da avaliação B. Isso é demonstrado quando se compara as respostas das turmas. Uma porcentagem bem menor de alunos na avaliação $A$ descreveram que o curso cumpriu as expectativas, enquanto esse quesito na avaliação $B$ foi 0 de maior destaque. A partir das lições obtidas o conteúdo programático vai sendo moldado, permitindo o planejamento de capacitações em novas áreas BIM para os gestores.
Cristiane L. Canuto

Pedro de Seixas Corrêa

Eduardo Ribeiro dos Santos

Cristiane Ramos Magalhães

Técia Duarte

1- PROARQ-UFRJ/FGV

cricanuto@gmail.com

2- FGV, pedro.seixas@fgv.br

3 -PROARQ-UFRJ/D5/FGV,

contato@duduribeiro.com.br

4- PROARQ-UFRJ/FGV /Firjan SENAI,

crisarqrj@gmail.com

5-FGV, temapedu@gmail.com

\section{INTRODUÇÃO}

A Formação Executiva em BIM é um curso de curta duração oferecido pela Fundação Getúlio Vargas (FGV). 0 curso tem como objetivo principal, desenvolver nos gestores as competências necessárias para liderar equipes, empresas e projetos no ambiente BIM, capacitando-os a atuar estrategicamente na implementação,

desenvolvimento e execução do projeto em suas diversas fases. As aulas são remotas, síncronas e transmitidas pela plataforma Zoom. As disciplinas têm caráter gerencial envolvendo todas as fases do ciclo de vida do empreendimento.

Esse trabalho apresenta os resultados alcançados nas turmas ocorridas entre outubro/2020 e março/2021. Foram ao todo 85 alunos distribuídos em 3 turmas, sendo uma turma fechada (para colaboradores de uma mesma empresa, do setor de infraestrutura) e 2 turmas abertas (com inscrição permitida a profissionais da Indústria da Construção Civil com formação superior).

\section{AGRADECIMENTOS}

Agradecemos a Fundação Getulio Vargas e a CAPES no apoio a este trabalho. 